\title{
Dampak Penggunaan Gadget Pada Pelajar Di SMP Negeri 33 Samarinda
}

\author{
Rosdiana \\ Universitas Widya Gama Mahakam Samarinda \\ anahanur@gmail.com \\ Kartina Wulandari \\ Universitas Widya Gama Mahakam Samarinda \\ kartina.wulandari@gmail.com \\ Godefridus Bali Geroda \\ Universitas Widya Gama Mahakam Samarinda \\ Godefridus88@gmail.com
}

\begin{abstract}
Abstrak
Gadget merupakan sebuah inovasi dari teknologi terbaru dengan kemampuan yang lebih baik dan fitur terbaru yang memiliki tujuan maupun fungsi lebih praktis dan juga lebih berguna. Seiring perkembangan Pengertian Gadget pun menjadi berkembang yang sering kali menganggap smartphone adalah sebuah gadget dan juga teknologi komputer ataupun laptop bila telah diluncurkan produk baru juga dianggap sebagai gadget.

Metode yang digunakan adalah kombinasi ceramah, diskusi, tanya jawab dan games, disesuaikan dengan karakteristik peserta, waktu, serta sarana yang tersedia.

Kegiatan ini dilaksanakan pada jam 09.00 - 11.00 WITA, hari Selasa tanggal 12 Desember 2017 di SMPN 33 Samarinda Kelurahan Bentuas Kecamatan Palaran. Peserta kegiatan seminar terdiri dari kelas VII A, VII B, VIII dan IX, total peserta 95 siswa, lokasi SMPN 33 Kelurahan Bentuas Samarinda. SMPN 33 berada di pedesaan yang jauh dari perkotaan sehingga gadget merupakan satu-satunya hiburan buat mereka. Walaupun di pedasaan jangkauan sinyal sangat memadai untuk menggunakan internet, sehingga tiap pelajar memiliki gadget/ smartphone. Berdasarkan hasil seminar dengan metode diskusi tanya jawab dan games dengan pelajar SMPN 33, menunjukkan bahwa hampir semua pelajar mengaku pernah mengakses informasi pornografi melalui situs di internet melalui gadget dalam bentuk gambar, vidio atau dalam permainan game.
\end{abstract}

Kata Kunci: Dampak, Gadget, Pelajar 


\section{Jurnal Abdimas Mahakam \\ https://journal.uwgm.ac.id/index.php/abdimasmahakam \\ Online ISSN : 2549-5755 \\ Januari 2018, Vol. 2 No. 1}

\section{Pendahuluan}

Gadget adalah sebuah istilah yang berasal dari bahasa Inggris, yang artinya perangkat elektronik kecil yang memiliki fungsi khusus. Dalam bahasa Indonesia, gadget disebut sebagai "acang". Salah satu hal yang membedakan gadget dengan perangkat elektronik lainnya adalah unsur "kebaruan". Artinya, dari hari ke hari gadget selalu muncul dengan menyajikan teknologi terbaru yang membuat hidup manusia menjadi lebih praktis. Contohcontoh dari gadget di antaranya telepon pintar (smartphone) seperti iphone dan blackberry, serta netbook (perpaduan antara komputer portabel seperti notebook dan internet).

Gadget kini sudah menjadi kebutuhan sehari-hari masyarakat modern, mulai dari laptop, tablet, ponsel atau ponsel pintar. Semua perangkat teknologi canggih tersebut tak sekadar menjadi alat komunikasi dan hiburan, tetapi juga untuk mengetahui berbagai informasi dan pengetahuan. Karenanya tak mengherankan bila banyak orang asyik menggunakan gadget hingga lupa waktu.

Perkembangan teknologi sekarang ini sangat pesat. Banyak teknologi canggih yang telah diciptakan, seperti gadget. Kemajuan teknologi membuat perubahan yang begitu besar dalam kehidupan manusia di berbagai bidang dan memberikan dampak yang begitu besar pada nilainilai kebudayaan. Sekarang ini setiap orang diseluruh dunia pasti sudah memiliki gadget. Tak jarang kalau sekarang ini banyak orang yang memiliki lebih dari 1 gadget. Ini mungkin disebabkan oleh beberapa faktor bahkan mempunyai gadget merupakan kebutuhan sekunder tetapi telah menjadi kebutuhan primer.

Guru Besar Ilmu Kedokteran Nuklir, Fakultas Kedokteran Unpad Prof. Dr. Djohan Mansjur,Sp.P.D.-KEMD, Sp.K.N menjelaskan radiasi secara umum memang menimbulkan perusakan pada jaringan sel. Misalnya penggunaan notebook atau komputer dapat merusak jaringan sel pada mata. Begitu juga pada pendengaran, secara umum gelombang elektromagnetik dapat mempengaruhi kromosom, sel, dan sperma. Dalam pendengaran terjadi proses pengionan yang juga berhubungan dengan kinerja otak. Bila intensitasnya sering dan tinggi bisa menjadikan seseorang menjadi pelupa atau cepat pikun. Sementara radiasi yang menyerang kromosom dapat mengakibatkan mutasi gen yang menurut Prof. Mansjur dapat mengarah pada terjadinya kanker. 


\section{Jurnal Abdimas Mahakam}

\section{https://journal.uwgm.ac.id/index.php/abdimasmahakam \\ Online ISSN : 2549-5755 \\ Januari 2018, Vol. 2 No. 1}

Lokasi SMPN 33 Kelurahan Bentuas Samarinda berada di pedesaan yang jauh dari perkotaan sehingga gadget merupakan satu-satunya hiburan buat mereka. Walaupun di pedasaan jangkauan sinyal sangat memadai untuk menggunakan internet, sehingga tiap pelajar memiliki gadget/ smartphone.

\section{Metode}

Metode yang digunakan adalah ceramah, diskusi, tanya jawab dan games, disesuaikan dengan karakteristik peserta, waktu, serta sarana yang tersedia.

Kegiatan ini dilaksanakan pada jam 09.00 - 11.00 WITA, hari Selasa tanggal 12 Desember 2017 di SMPN 33 Samarinda Kelurahan Bentuas Kecamatan Palaran. Peserta kegiatan seminar terdiri dari kelas VII A, VII B, VIII dan IX, total peserta 95 siswa.

\section{Hasil dan Pembahasan}

Berdasarkan hasil seminar dengan metode diskusi tanya jawab dan games dengan pelajar SMPN 33, menunjukkan bahwa hampir semua pelajar mengaku pernah mengakses informasi pornografi melalui situs di internet melalui gadget dalam bentuk gambar, vidio atau dalam permainan game.
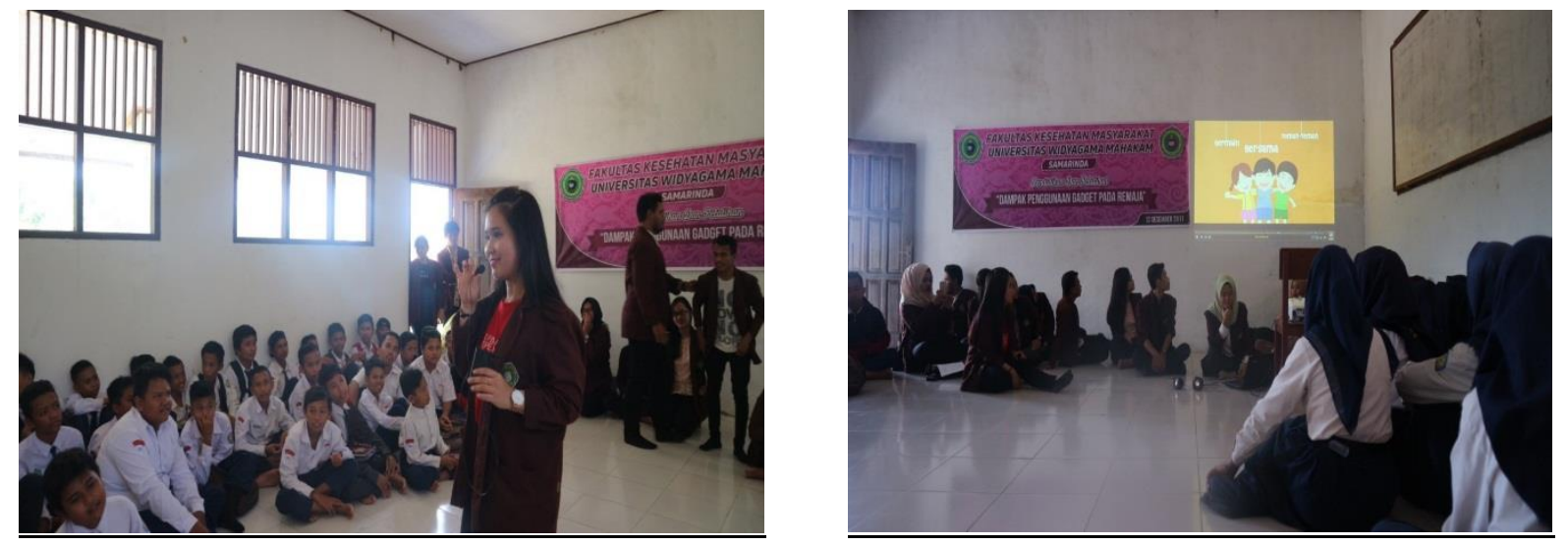

Narkolema adalah narkoba lewat mata. Maksud sebenarnya adalah pornografi yang biasanya diakses manusia lewat mata ternyata memiliki daya rusak sebagaimana penggunaan narkoba. Karena itulah digunakan istilah narkolema. Memang benar bahwa masalah pornografi di negeri kita pada saat ini semakin membuat miris. Menurut data dari Kementerian Komunikasi dan Informatika (Kemenkominfo) Indonesia kini sudah menduduki peringkat pertama 


\section{Jurnal Abdimas Mahakam \\ https://journal.uwgm.ac.id/index.php/abdimasmahakam \\ Online ISSN : 2549-5755 \\ Januari 2018, Vol. 2 No. 1}

sebagai negara pengakses situs pornografi via internet. Padahal tahun 2007 yang lalu Indonesia masih ada di urutan kelima. Parahnya, diantara pengakses situs pornografi tersebut adalah anak-anak. Berdasar riset sebuah LSM tahun 2010 menunjukkan bahwa 96\% anakanak Indonesia pernah membuka konten pornografi di internet. (suarapembaruan.com, 14 November 2013).

Dulu hal-hal yang berbau pornografi ditutup-tutupi dan tabu untuk dibicarakan. Namun sekarang pornografi sudah semakin terbuka dan menjamur di masyarakat bahkan bisa diakses dengan mudah di rumah, di kantor, di sekolah, di tempat-tempat ibadah, di pasar/mall, dll. Teknologi berperan besar dalam penyebaran pornografi. Siapapun hanya dengan menekan tombol tertentu pada gadget yang dipegang, sudah mendapatkannya.

Sebagaimana pengguna narkoba yang dapat mengalami kecanduan, pengguna pornografi (narkolema) juga dapat mengalami hal yang sama. Bagaimanakah seseorang bisa mengalami kecanduan narkolema? Penelitian ilmiah menunjukkan proses kecanduan narkolema dapat digambarkan sebagai berikut: manusia memiliki PRC (Pre Frontal Cortex) yaitu bagian otak yang berfungsi untuk pusat pertimbangan dan pengambil keputusan. Bagian inilah yang tidak ada pada otak binatang, jadi PRC hanya ada pada manusia saja. PRC mudah rusak karena benturan fisik, zat kimia, narkotika, napza dan narkolema/pornografi. Sistem limbik yang mengatur emosi, makan, minum dan naluri seksual di dalam otak akan mengaktifkan zat kimia otak dopamine yang memberi rasa senang, penasaran dan kecanduan. Dopamine juga akan aktif jika seseorang mengkonsumsi narkoba sehingga candu narkoba sama dengan candu narkolema. Otak akan mengingat apa saja yang akan memberi kesenangan. Secara alamiah dopamine dialirkan oleh sistem limbik ke PRC dimana pada orang yang kecanduan narkolema akan mengalirkan dopamine secara berlebihan ke PRC sehingga membanjiri PRC dan PRC menjadi tidak aktif karena terendam dopamine. Semakin sering PRC tidak aktif maka akan mengerut dan fungsinya terganggu dan sistem limbik akan berkembang semakin besar karena selalu mengaktifkan dopamine.

Jika pengguna narkolema dibiarkan saja maka akan menjadi pelanggan narkolema seumur hidup dan mengalami kerusakan pada PRC. Awalnya pengguna narkolema akan mengalami gangguan konsentrasi, menurunnya kemampuan dalam menimbang benar dan salah, serta berkurangnya kemampuan mengambil keputusan. Pengguna narkolema akan mengalami 


\section{Jurnal Abdimas Mahakam}

\section{https://journal.uwgm.ac.id/index.php/abdimasmahakam \\ Online ISSN : 2549-5755 \\ Januari 2018, Vol. 2 No. 1}

penyimpangan seksual, menganggap pernikahan itu tidak penting dan orang lain hanya dianggap sebagai obyek seksual semata. Menurut ahli bedah otak, pecandu narkolema mengalami kerusakan pada lima bagian otak yang sama seperti pada kerusakan otak yang disebabkan oleh benturan fisik ataupun zat kimia narkoba. Lima bagian otak yang rusak adalah Orbito frontal, Midfrontal, Insula hippo campus temporal, Nucleus accumbers patumen, Cingalute dan Cerebellum.

Selain menjadi sebab terjadinya kerusakan otak permanen narkolema juga menjadi pemicu terjadinya berbagai perzinahan, seperti: pelecehan seksual, perkosaan, seks bebas, dll, yang semua itu menjadi sebab munculnya berbagai penyakit dan bencana kemanusiaan. Karena selain menyebabkan terjadinya bahaya penyakit fisik, perzinahan juga merusak kehormatan dan garis keturunan/nasab manusia.

\section{Simpulan dan rekomendasi}

Melihat betapa besarnya dampak buruk, bahaya dan bencana yang bisa timbul dari penggunaan gadget, dengan bebas mengakses informasi pornografi melalui konten vidio, gambar dan game. Sudah sepatutnya umat manusia menyatakan perang terhadap narkolema. Karena itu narkolema tidak boleh dianggap remeh. Perlu kerja sama semua pihak agar menutup konten-konten narkolema di dunia maya. Menghimbau para orang tua agar sering memeriksa gadget anak-anaknya dan mendampingi pada saat menggunakan gadget. 


\section{Jurnal Abdimas Mahakam \\ https://journal.uwgm.ac.id/index.php/abdimasmahakam \\ Online ISSN : 2549-5755 \\ Januari 2018, Vol. 2 No. 1}

\section{Daftar Pustaka}

Anwa M. 2014. Pemberdayaan Masyarakat Era Global.Bandung:Alfabeta

Ajzen, I., 1971. Sikap Normatif Pesan: Sebuah Penelitian Efek Diferensial Komunikasi Persuasif terhadap Perilaku. Sosiometri, Vol 34, 263-280.

------., 1991. The Theory of Planed Behavior : Organizational Behavior and Human Decision Processes, Vol 50, 179-211.

-------., 2002. "Perceived Behavioral Control, Self-Efficacy, Locus of Control, and the Theory of Planned Behavior.” Journal of Applied Social Psychology 32, 1-20.

Azwar, S., 2007. Sikap Manusia Teori dan Pengukurannya, Edisi 2 Cetakan ke 7,

Yogyakarta : Pustaka Pelajar.

Basaran Zekiye.2016. The effect of sportive and cultural activities on the self-esteem and hope of the children who have tendency to involve in a crime. Academic Journal of Educational Research and Reviews. Vol. 11(14), pp. 1324-1330, 23 July, 2016.

Badan Narkotika Nasional 2009. Berpikirlah Sehat Tanpa Narkoba. Pikiran Rakyat Hal 30 Bandung. Magister Kesehatan Bidang Kesehatan Anak dan Remaja, Ketua Ikatan Dokter Indonesia Kabupaten Cirebon, dan Ikatan Dokter Anak Indonesia Cabang Jawa Barat

Badan Narkotika Nasional. 2006, Ada Apa dengan Pra Remaja Kita. Serial Inspirasi Pengasuhan Untuk Pra Remaja. Pusat Dukungan Pencegahan BNN

Bandura, A., 1986. Social Foundation of Thought and Action : A Social Cognitive Theory. Englewood Cliffs, NJ : Prentice Hall.

-------., 1997. Self Efficacy: The Exercise of Control. New York: Freemanand Company. -------., 2002. Social Cognitive of Mass Comunication In J Briandt and D Zillman (eds),

Media Effects; Advanced in the Teory and Research (2nd ed) Hillsdale, N J: Erlbaum.

Fishbein, M., dan Ajzen., I. 1975. Belief, Attitude, Intention, and Behavior: An Introduction to Theory and Research. Reading, Mass : Addison-Wesley.

Fitriana, R., Nur, D. R., \& Arbain, A. (2017). Pelatihan dan Simulasi IELTS bagi Mahasiswa dan Dosen di Lingkungan Fakultas Pendidikan dan Keguruan Program Studi Bahasa Inggris Universitas Widya Gama Mahakam Samarinda. Jurnal Abdimas Mahakam, 1(2), $88-95$. 


\section{Jurnal Abdimas Mahakam}

\section{https://journal.uwgm.ac.id/index.php/abdimasmahakam \\ Online ISSN : 2549-5755 \\ Januari 2018, Vol. 2 No. 1}

Fitriana, Sinta., 2011. Promosi Kesehatan. Yogyakarta : Graha Ilmu.

Gottlieb, B.H., 2003, Sosial Support Strategies (Guidelines for Mental Health Practice), Sage Publications Inc., California.

Ife J dan Tesoriero. F., 2008. Community Development: Community-Based Alternatives in on Age of Globalization. Terjemahan Yogyakarta : Pustaka Pelajar.

Kickbusch I. 1997. Health Promotion in Canada: A Case Study. Fourth International Conference on Health Promotion. Jakarta : WHO.

Listiani E., Baksin A.2013. Media Dan Komunikasi Lingkungan. Bandung: Buku Litera

Maibach E.W, Cotton, D. 1995. Moving People to Behavior Change: A Staged Social Cognitive Approach To Message Design. In Maibach, E. W. and Parrott, R. L. (eds), Designing Health Messages: Approaches FromCommunication Theory and Public Health Practice. Sage,Thousand Oaks, CA, pp. 41-64.

Mardikanto, T. 2010. Konsep-konsep Pemberdayaan Masyarakat. Surakarta : UNS Press

Marilyn M.( 1998). Keperawatan Keluarga : Teori dan Praktik. Jakarta : EC

Notoatmodjo, S. 2003. Pendidikan dan Perilaku Kesehatan. Jakarta : Rineka Cipta.

Notoatmodjo S. 2007. Promosi Kesehatan \& Ilmu Perilaku.Jakarta: PT.Rineka Cipta

Ristianti A. 2012. Hubungan antara Dukungan Sosial Teman Sebaya dengan Identitas Diri pada Remaja di SMA Pusaka 1 Jakarta : Psikoligi Univ. Unidarma.

Sintadewi Ni Luh D, Suarni Ni Ketut, Arum Dewi W.M.P. 2014. Efektifitas Model Konseleing Behavioral Teknik Modeling Untuk Meningkatkan Efikasi Diri Siswa Kelas VIII SMP Nengeri 2 Singaraja Tahun Pelajaran 2013/2014. E-journal Undiksa Jurusan Bimbingan Konseling Volume: 2 No 1, Tahun 2014

Taura A.A, Abdullah Maria C, Roslan S and Omar Zoharah.2015. Relationship between selfefficacy, task value, self-regulation strategies and active procrastination among preservice teachers in colleges of education. International Journal of Sociology and Counseling. Vol 7(2).pp.11-17.March 2015 


\section{Jurnal Abdimas Mahakam}

https://journal.uwgm.ac.id/index.php/abdimasmahakam

Online ISSN : 2549-5755

Januari 2018, Vol. 2 No. 1

Tarik Sevindi. 2013. The relationship between general self-efficacy belief and burnout level among Turkish academicians. Academic Journal of Educational Research and Reviews. Vol. 8(24), pp. 2255-2259, 23 December, 2013 